\title{
Local, nacional e universal nos estudos históricos de Educação Comparada: o caso das Ações Afirmativas na era genômica
}

\section{Local, national and universal views in historical studies on Comparative Education: the case of Affirmative Actions in the genomic age}

\author{
Artur José Renda Vitorino ${ }^{1}$
}

\begin{abstract}
RESUMO
Este texto procura lançar as bases de uma interrogação pela Educação Comparada, se o nacional ainda tem lugar nas novas circunstâncias geradas pela globalização. Defende-se, a partir do caso das Ações Afirmativas na era genômica, que o valor heurístico da polarização entre o particular e o geral, ou entre o local e o universal, é útil tanto para a compreensão de fenômenos que eram baseados, especialmente, no território e nos Estados nacionais, quanto para o entendimento das identidades culturais e afetivas existentes no grande panorama da mundialização. Conclui-se, quanto às modificações materializadas pelo Estado-Nação nos processos de regulação dos sistemas educacionais, no que diz respeito aos meios de geração de identidades culturais e afetivas étnicas, que a despeito de o fenômeno da Globalização nos forçar a pensar que as fronteiras nacionais estão sendo rompidas e ultrapassadas, o nacional (e, a reboque, o local/ particular) tem lugar nas novas circunstâncias geradas pela Globalização, pois o Estado-Nação continua a induzir a formação de narrativas com o fim de ser ele o gerador da identidade oficial, e esse controle é exercido, especialmente, por intermédio do sistema de ensino.
\end{abstract}

Palavras-chave: Educação Comparada; políticas públicas; Estado Democrático; globalização; questão étnica.

DOI: $10.1590 / 0104-4060.28088$

1 Pontifícia Universidade Católica de Campinas. Programa de Pós-Graduação em Educação. Campinas, São Paulo, Brasil. Rod. Dom Pedro I - Km 136, Parque das Universidades. CEP: 13086-900. 


\begin{abstract}
This paper seeks to lay the foundations of an interrogation by the Comparative Education if the national view still has its place in the new circumstances created by globalization. It defends, from the case of Affirmative Actions in the genomic era, that the heuristic value of the polarization between the particular and the general, or between the local and the universal, is useful both for understanding the phenomena based especially on the territory and on national states, and for understanding the cultural and affective identities existing in the big picture of globalization. In conclusion, regarding the modifications embodied by the nation-state in the process of regulation of educational systems considering the means of generating cultural and affective ethnic identities, despite the fact that the phenomenon of globalization force us to think that national borders are being broken and outdated, the national view (and the counterpoint, the local/particular) has its place in the new circumstances created by the globalization, as the nation-state continues to induce the formation of narratives in order to be the generator of the official identity, and this control is exercised particularly through the education system.
\end{abstract}

Keywords: Comparative Education; public policies; Democratic State; globalization; ethnic issues.

\title{
Local e global
}

É um truísmo afirmar que, com a globalização, novas redes de sociabilidade são formadas e que elas saltam as fronteiras geográficas e culturais, dando-nos a impressão de que as relações humanas no espaço e no tempo foram intensificadas. Essa nova realidade estaria a promover novas formas de conhecimento e de expressão, cujo papel do nacional esmaece no inverso quadrado do aumento das forças supranacionais. Curiosamente, com o fenômeno da globalização, novas formas de identidades culturais e afetivas - não mais, tão somente, baseadas no território e, menos ainda, no Estado-Nação - estão fazendo florescer não só o que seria sistêmico e universal, mas, principalmente, o que é miúdo e local. No limite, ganham cada vez mais destaque os aspectos da vida individual e a subjetividade.

No entanto, no que tange à emergência de sistemas de validade universal, como o seria o sistema educacional, os estudos Históricos de Educação Comparada estão nos mostrando que havia um concerto de formações de sistemas educacionais similares mesmo quando as identidades culturais e afetivas eram 
baseadas tão somente no território e no Estado-Nação ${ }^{2}$. O valor heurístico da polarização entre o particular e o geral, ou entre o local e o universal, é útil tanto para a compreensão de fenômenos que eram baseados, especialmente, no território e nos Estados nacionais, quanto para o entendimento das identidades culturais e afetivas existentes no grande panorama da mundialização.

Procede-se, nas seções seguintes, a uma síntese da investigação quanto às modificações materializadas pelo Estado-Nação nos processos de regulação dos sistemas educacionais no que diz respeito aos meios de geração de identidades culturais e afetivas étnicas, como se elas fossem o resultado de um processo mais largo de regulação transnacional.

\section{O Estado-Nação na questão racial}

No Brasil, as medidas legais estabelecidas pelas disposições antidiscriminatórias na Constituição Federal de 1988 transformaram o racismo em crime inafiançável, protegeram a manifestação das culturas indígenas e afro-brasileiras, determinaram a proteção legal aos documentos e locais dos antigos quilombos e garantiram o reconhecimento das terras ocupadas pelos quilombolas remanescentes. A Lei n. ${ }^{\circ} 10.558$, de 13 de novembro de 2002 (BRASIL, 2002), por meio da Medida Provisória n. ${ }^{\circ}$ 63, estabeleceu a criação do Programa Diversidade na Universidade, no âmbito do Ministério da Educação, com a finalidade de programar e avaliar estratégias para a promoção do acesso ao ensino superior de pessoas pertencentes a grupos socialmente desfavorecidos, especialmente, dos afrodescendentes e dos indígenas brasileiros. A Lei n. ${ }^{\circ} 12.288$, de 20 de julho de 2010 (BRASIL, 2010), criou o Estatuto da Igualdade Racial. No mesmo intuito, foi instituída a Lei n. ${ }^{\circ}$ 10.639, de 9 de janeiro de 2003 (BRASIL, 2003), que estabeleceu a obrigatoriedade do ensino de história e cultura afro-brasileiras e africanas na educação básica, seguida pela publicação das "Diretrizes curriculares nacionais para a educação das relações étnico-raciais e para o ensino de história e cultura afro-brasileira e africana", cujo parecer e a resolução foram aprovados pelo Conselho Nacional de Educação (CNE) em março de 2004 e homologados pelo Ministério da Educação (MEC) em junho desse mesmo ano. A resolução foi resultado do Parecer $\mathrm{CNE} / \mathrm{CP} 3 / 2004$, que teve como relatora a conselheira Petronilha Beatriz Gonçalves e Silva, da Câmara de Educação Superior do CNE (ABREU; MATTOS, 2008).

2 Trata-se do que foi designado e desenvolvido como "Cultura Educacional Mundial Comum” por John Meyer et al. (1997) e demais pesquisadores de Stanford (Califórnia). 
Essas medidas legais devem ser compreendidas como próprias de regimes democráticos. Neles, necessariamente, a igualdade e a liberdade são os princípios estruturadores da sociedade, pelos quais o indivíduo é colocado como o principal ponto de referência. A coexistência desses dois ideais, no entanto, quando a igualdade levada ao extremo limita a liberdade e vice-versa, caracteriza grande parte dos principais conflitos passados e contemporâneos das democracias. Paralelamente, considera-se que, para corrigir determinadas desigualdades (sejam elas de ordem social, racial/ étnico, de gênero), o Estado democrático deve intervir na sociedade para corrigir as suas desigualdades, pois é argumentado que a anterioridade fundacional do conceito de igualdade e uma consequente desinflação do conceito de liberdade ajudam na melhor compreensão da séria questão do pluralismo nas sociedades democráticas e, também, do próprio papel do cidadão nas democracias (RAWLS, 2000a, 2000b, 2003).

É nessa relação entre o Estado, a Sociedade e o Indivíduo que se deve buscar compreender a ação do Estado democrático-liberal brasileiro quanto à questão racial, por meio da educação, em que se destacam os seguintes aspectos: a) mesmo sofrendo as influências de medidas sociais ocorridas em outros países - especialmente, as realizadas nos Estados Unidos, as denominadas "ações afirmativas" -, a questão racial ainda é um tema a ser resolvido, a partir do que Nancy Fraser (2009, p. 11) denominou de "enquadramento Keynesiano-Westfaliano", pelo qual, em regra, as discussões acerca da justiça concernentes às relações entre os cidadãos deveriam “[...] submeter-se ao debate dentro dos públicos nacionais e contemplar reparações pelos Estados nacionais"; b) a anterioridade fundacional do conceito de igualdade e uma consequente desinflação do conceito de liberdade significam que os conceitos de liberdade e de igualdade estão definidos a partir da estrutura de poder, cuja liberdade é uma liberdade externa pela qual temos o poder de realizar, também, aquilo que os outros indivíduos fazem, porque, anteriormente, considera-se que um indivíduo é igual ao outro indivíduo, e os extremos da liberdade individual são coibidos e sofrem as sanções de um poder que é externo ao indivíduo, é mais forte do que ele e tem força de lei, mediante o "enquadramento Keynesiano-Westfaliano"; c) a anterioridade fundacional do conceito de igualdade e uma consequente desinflação do conceito de liberdade significam que o indivíduo é considerado como um ser empírico que não pode ser modificado pela educação, ou seja, o indivíduo é um ser acabado que não se altera por nenhuma ação interna ou externa a ele.

Como desdobramento do exposto, conclui-se: i) o Estado democrático, ao intervir na sociedade para corrigir as desigualdades de ordem racial por meio de políticas públicas pela educação, produz a sobreposição da igualdade sobre a liberdade e suprime o pressuposto básico, intrínseco à educação, que é a formação da pessoa no sentido de lhe conceder e permitir a sua autonomia 
moral, a sua liberdade interna. A igualdade democrática permite a existência de um indivíduo multidimensional, porém, dependente de uma estrutura de poder que, paradoxalmente, impede a existência da independência do sujeito, anulando a pessoa; ii) apesar de os Estados democráticos expressarem que o indivíduo é colocado como o seu principal ponto de referência, a argumentação e consequente implementação de que a anterioridade fundacional do conceito de igualdade e uma consequente desinflação do conceito de liberdade ajudam na melhor compreensão da séria questão do pluralismo nas sociedades democráticas, o Estado democrático desloca a autoridade individual para a autoridade do Estado de caráter impessoal; iii) ao deslocar a autoridade individual para a autoridade do Estado, o Estado democrático considera que a ordem das sociedades não significa a existência de uma correspondência entre estrutura da alma humana e a das sociedades, e sim o contrário, pois a democracia igualitária reconhece o estado de desordem em que vive a alma do indivíduo e aproveita-se desse estado de desordem para realizar certos objetivos sociais que, arbitrariamente, são considerados estimáveis para o bom funcionamento da sociedade; iv) na democracia igualitária, cuja verdadeira mola é o princípio perverso do self-enlightened interest, este princípio é motivo de precaução em função da estrutura paralela e da comunhão ideológica entre o liberalismo e o totalitarismo (VOEGELIN, 1975, 2000).

Defende-se que na relação entre liberdade e igualdade, a liberdade deve ser entendida não como liberdade externa derivada da ideia de justiça a partir da Estrutura de Poder, e sim, como liberdade interna por meio da Estrutura de Cultura, pela qual a pessoa humana é que é o centro autônomo de decisões éticas. Assim definida, na liberdade interna, como autodeterminação da pessoa humana em contraposição à liberdade como faculdade de escolha, desconsidera-se a liberdade como faculdade de escolha do material a ser utilizado na construção de uma nova sociedade, e, assim, imediatamente, evita-se chegar ao problema da indeterminação, da liberdade negativa, porque, neste último sentido, a liberdade precisa ser suprimida, uma coerção precisa ser exercida para evitar as consequências de tal exercício da liberdade, em prol dos interesses da Sociedade ou do Estado (MELLO, 2000).

\section{A proeminência do Estado-Nação}

O Estado, como sistema de ordenamento de justiça, operando uma formulação da existência de uma comunidade imaginária, em nome da qual, decisões 
são tomadas, também é formado por diversos poderes, articulando-se a certas instituições sociais, conforme nos ensinou Michel Foucault, que tanto conformam os indivíduos quanto os dominam (GIANNOTTI, 2003).

Para além do poder do Estado, representante de uma totalidade em nome da qual se exerce o monopólio da força legítima, o poder estatal também se constitui de dispositivos, matrizes, conformando condutas e pensamentos, tecendo uma rede de micropoderes, cujo fim, mais do que conformar a agenda dos dominados, é estruturar atitudes, comportamentos e subjetividades, socializando indivíduos, a fim de respeitarem fronteiras e hierarquias.

Em outras palavras, o Estado, ao parecer atender às demandas reivindicadas pelos movimentos negros antirracismo, formulou políticas públicas de ação afirmativa que parecem aceitar afiliações voluntárias, as quais possibilitariam às pessoas adotar identidades múltiplas. Por intermédio de leis, parece que o Estado está vicejando a criação de oportunidades para os segmentos da população historicamente discriminada.

Seria um paradoxo, pois as possibilidades de alguém adotar identidades múltiplas poriam fim à ideia de que o indivíduo pertenceria a um grupo homogêneo de identidade ideal sem fissuras - ideia-chave para criação e perpetuação do Estado-Nação -, ou seja, não teria sentido para o poder soberano, o Estado, a própria Nação estimulando a convivência, dentro de si, de várias Nações.

O Estado, em suas ações antirracistas, mediante seus ordenamentos de justiça, parece querer assumir, ao mesmo tempo, o princípio universalista e o princípio diferencialista, aquele como princípio da igualdade de todos os cidadãos perante a Lei, e este, o princípio da diferença, para embasar uma política de direitos específicos para cada grupo ou minoria racial (AZEVEDO, 2004).

Talvez devamos entender que o Estado está se ajustando à emergência de um novo poder, que, ao mesmo tempo, é global e microscópico. Paralelamente à sociedade disciplinar, estaria nascendo uma sociedade de controle, onde os mecanismos de comando se entranham de tal modo no corpo social, afetando corpos e cérebros, que terminam por orquestrar uma forma de vida. No caso brasileiro, notamos, o poder estatal continua se pondo como a verdade de uma população, o espelho no qual ela desenha a sua identidade, transcendendo às condutas daqueles que operam em seu nome. Pois, como compreender as mudanças da política racial pelo Estado, pela qual a população brasileira deve assumir e interiorizar uma taxonomia bipolar (preto ou branco)?

Há tempos que os negros, no Brasil, estão reivindicando os seus direitos, sobretudo, como reparação social do seu passado escravista. Em resposta, tardia, o Estado brasileiro, com a sua última Constituição de 1988, valida e institucionaliza que membros de uma determinada cultura possam usar direitos políticos de cunho individualista, no exercício de sua autonomia pública, para proteger 
a identidade de suas próprias culturas. Concomitantemente, a sobrevalorização da cultura, cuja ênfase recai em considerar a esfera cultural como a moldura principal ou exclusivista para o crescimento do homem, está permitindo uma tendência teórica que vem se difundido, cada vez mais, no sentido de efetuar as análises sociais e históricas sobre contextos particulares, em oposição às grandes totalizações do passado. Como reflexo imediato desse particularismo cultural e normativo, há uma atuação para que a educação formal seja diferente e, paradoxalmente, sob a forma de direitos coletivos. Há de se estabelecer uma distinção entre cultura política e cultura no sentido etnográfico, criticar o approach particularista e defender o universalismo, pois as públicas políticas afirmativas, sub-repticiamente, introduzem um controle pelo Estado sobre os agentes sociais que buscam ter o direito de viver e educar os seus filhos no contexto cultural em que eles próprios se reconhecem como pessoas e encontram a sua identidade.

\section{As identidades na era genômica}

Para quem está interessado no estudo da história da ideia de raça, o contributo de Eric Voegelin (1997) mostrou que, desde John Ray ${ }^{3}$ até Carl Gustav Carus $^{4}$, e até mesmo George Louis Leclerc de Buffon ${ }^{5}$, todos eram racistas. Por trás de uma nomenclatura das espécies biológicas havia, também, a criação de um sistema que as classificava como raças completamente distintas, cuja ideia foi estereotipada ao longo do século XIX.

Assim como a ideia de raça tem uma data de nascimento, conforme nos ensinou Voegelin (1997), a ideia de que a História do Brasil é singular na História

3 John Ray - Ray também escrito (até 1670) Wray (nascido em 29 de novembro de 1627, Black Notley, Essex, Port. morreu em 17 de janeiro de 1705, Black Notley) -, naturalista Inglês do século XVII, foi um botânico que contribuiu significativamente para o progresso na taxonomia. Seu legado duradouro à botânica deve-se à sua concepção da expressão “espécies", como a unidade última da taxonomia.

4 Carl Gustav Carus (03 de janeiro de 1789-28 de julho de 1869) foi um fisiologista alemão e pintor, nascido em Leipzig. Homem de muitas facetas, pois foi médico, naturalista, cientista, psicólogo e pintor, na área da ciência, seu contributo foi definir o conceito do arquétipo dos vertebrados, uma ideia seminal no desenvolvimento da teoria da evolução de Darwin.

5 Georges Louis Leclerc, o conde de Buffon (1707-1788), filósofo e biólogo naturalista francês, como observador da natureza e ávido leitor de história natural, tornou-se membro da Académie Royale des Sciences (1733) e foi nomeado intendant em Jardin du Roi (1740), onde iniciou um minucioso trabalho de classificação das espécies vegetais e animais. Nesse trabalho, usou um método de classificação natural estabelecendo a existência dos princípios de continuidade e de afinidade entre as espécies, concepção oposta ao método artificial utilizado por Lineu. 
das Nações porque os brasileiros são fruto de uma miscigenação nasceu com o naturalista Karl Friedrich von Martius ${ }^{6}$.

Com o programático texto intitulado Como se deve escrever a História do Brasil, escrito pelo naturalista Karl Friedrich von Martius e publicado na Revista Trimensal de Historia e Geographia (número 24, janeiro de 1845, p. 389-411), o cerne da singularidade da história do Brasil - "país que tanto promete" - no rol da História das civilizações seria que, no país, foi formada uma população a partir da convergência e mescla "[...] de um modo particular de três raças, a saber: a de cor de cobre ou americana, a branca ou caucasiana, e enfim a preta ou etiópica" (MARTIUS, [1845] 1982, p. 87). A partir da “[...] reunião e contato de tão diferentes raças humanas, podemos avançar que a sua história se deverá desenvolver segundo uma lei particular das forças diagonais" (MARTIUS, [1845] 1982, p. 87). Esse texto de von Martius inaugura, de forma simbólica, as seguintes perspectivas que serão desenvolvidas, posteriormente, pelas obras historiográficas:

a) a forte constituição simbólica da identidade nacional brasileira como uma "mescla" das três raças: a miscigenação, no sentido racial, étnico e cultural;

b) a contribuição histórica de cada uma das três raças na constituição da História do Brasil, especialmente, "[...] o sangue português, em um poderoso rio, [que] deverá absorver os pequenos confluentes das raças índia e etiópica" (MARTIUS [1845] 1982, p. 88), pois o português, "[...] como descobridor, conquistador e senhor", "[...] deu as condições e garantias morais e físicas para um reino independente; que o português se apresenta como o mais poderoso e essencial motor" para a consecução da "[...] vontade da providência [que] predestinou ao Brasil esta mescla" de raças "[...] para alcançar os mais sublimes fins na ordem do mundo" (MARTIUS [1845] 1982, p. 88).

Essa tradição interpretativa da "miscigenação" legada por von Martius, de atribuir sentido à história da formação da identidade nacional brasileira por meio da tríade meio/ raça/ cultura, foi capaz de gerar a resolução da "lei particular das

6 Carl Friedrich Philipp Von Martius (1794-1868), botânico e antropólogo, descendente de Galeotto Martio, humanista italiano que emigrou, no século XV, para a Hungria e de lá para a Alemanha, esteve no Brasil de 1817 a 1820, integrando uma missão científica que acompanhou a arquiduquesa dona Leopoldina, depois imperatriz do Brasil. Percorreu todo o país e escreveu grandes obras científicas e antropológicas, além de um texto ficcional, dentre elas: a Historia $\mathrm{Na}$ turalis Palmarum, O Estado de Direito entre os autóctones (1832); O passado e o futuro dos seres americanos (1839); Os nomes de plantas de língua tupi (1858); Glossaria Linguarum Brasiliensium (1863); o breve tratado Como se deve escrever a Historia do Brasil (1842); a obra ficcional Frei Apolônio (1831). 
forças diagonais". Ela foi transformada por Gilberto Freyre, em Casa-Grande \& Senzala ([1933] 1954, p. 20), na lei "do equilíbrio entre os antagonismos", criador da "democracia social" no período colonial da formação do Brasil.

A harmoniosa miscigenação racial brasileira foi um mito forjado por von Martius, que procurava com a narrativa histórica dar uma unidade à recém nação brasileira. Tal unidade histórica era mais um elemento ideológico da "direção" saquarema tramada no século XIX - como a denominou Ilmar R. Mattos (1987). A urdidura semântica da unidade nada mais era do que o resultado do princípio de que, se não se compreende tudo, não se pode explicar coisa alguma, é própria de uma narrativa mítica, conforme nos ensinou Claude Levi-Strauss $(2010,2007)$.

Por meio de outros argumentos, ao longo das décadas de 1940, 1950, 1960, inúmeros pesquisadores criticaram a tese da "democracia racial brasileira" atribuída, especialmente, à obra Casa-Grande \& Senzala de Gilberto Freyre ${ }^{7}$. A tônica recaía em afirmar que, no Brasil, existia e existe o preconceito com base na cor da pele da pessoa (fenótipo); portanto, foi desenvolvida, por detrás do mito da "democracia racial", uma forma de discriminação "racial" (FRY, 2005).

Os atuais resultados de pesquisas na área da genética (ou genômica) estão trazendo novas narrativas que vão ao encontro da narrativa de von Martius. $\mathrm{O}$ resultado do que é muitíssimo novo (a Genômica), que, consequentemente, interage e também atrita com o muito antigo (raça e tipologias), ao mesmo tempo, volta a afirmar que o local e lugar Brasil traz uma universalidade, quando se quer debater questões envolvendo raça e racismo.

Centrado em Queixadinha, um povoado rural, minúsculo e pobre, no Vale do Jequitinhonha, no norte de Minas Gerais, com o fim de realizar pesquisas sobre as características genéticas da população brasileira baseadas na análise do DNA mitocondrial, do cromossomo $\mathrm{Y}$ e do DNA nuclear ${ }^{8}$, o trabalho do geneticista Sérgio Danilo Pena apontou a impropriedade do conceito de raça do ponto de vista biológico. Em artigo publicado em 2003, foi demonstrado que, no Brasil, a correlação entre cor e ancestralidade genômica era muito frágil. Ou seja, em nível individual, é praticamente impossível inferir a ancestralidade genômica de um brasileiro a partir de sua cor e vice-versa (PENA et al., 2003).

Paralelamente às "guerras de narrativas" em torno dos dilemas das identidades na era genômica (SANTOS; MAIO, 2005), campo de disputa no qual participam, entre outros, biólogos, cientistas sociais e movimentos sociais, essa nova genética traz, também, novos elementos no terreno das guerras de história

7 Refere-se aqui, especialmente, aos trabalhos pioneiros de Donald Pierson, nos anos 1940, passando pelos estudos da Organização das Nações Unidas para a Educação, a Ciência e a Cultura (UNESCO), nos anos 1950, e os trabalhos da chamada "escola paulista", nos anos 1960.

8 DNA, em inglês: deoxyribonucleic acid. ADN, em português: ácido desoxirribonucleico. 
escolar. Isso porque as discussões acerca da polissemia do tema "raça" no ambiente escolar - sobretudo entre os docentes, mais do que dos docentes com os alunos - ganha novos contornos sobre a recepção e a prática da legislação recente sobre o ensino de história e cultura afro-brasileiras e africanas (PEREIRA, 2011). Mas é um novo com cara de coisa muito antiga e que, paradoxalmente, faz de Queixadinha um modelo local que ganha universalidade, enquanto modelo analítico para fins de estudos genômicos sobre raça e diversidade biológica do povo brasileiro, no início do século XXI, equivalente ao que representavam as pesquisas de naturalistas como Karl Friedrich von Martius sobre a mescla de raças na constituição do Estado brasileiro e da Nação brasileira, em meados do século XIX, e semelhante, também, às pesquisas sobre as comunidades rurais tradicionais do interior da Bahia, na década de 1950, coordenadas por Charles Wagley, nos estudos estimulados pelo projeto da Organização das Nações Unidas para a Educação, a Ciência e a Cultura (UNESCO), no Brasil. Em meio às investigações promovidas pela UNESCO no pós-holocausto, Charles Wagley ${ }^{9}$ enfatizava, na introdução de Race and Class, que

[...] o mundo tem muito a aprender com o estudo das relações raciais no Brasil [...]. Os vários projetos sobre o tema das relações raciais, os quais foram estimulados pelo projeto UNESCO no Brasil, devem dar pela primeira vez um conhecimento objetivo da situação tal como ela existe sob uma variedade de condições por todo este vasto e diversificado país (WAGLAY, 1952, p. 8-9, apud SANTOS; MAIO, 2005).

As narrativas genéticas interagem com narrativas históricas e sociais, nas quais se notam enfrentamentos de diversos grupos aptos a pleitear o domínio simbólico de um determinado campo, inclusive do campo pedagógico, que busca informar, dirigir e conformar como as leis e diretrizes educacionais devem ser efetivadas no ambiente escolar pelos professores, não mais compreendido como transposição didática, e, sim, a partir de um confronto entre diversos agentes intra, extra e inter-relacionados à educação, cuja hierarquização interna e suas

9 Charles Wagley (1913-1991) foi um antropólogo americano que ajudou no desenvolvimento pioneiro da antropologia brasileira. Quando realizou sua pós-graduação, na década de 1930, na Universidade de Columbia, e sob a influência de Franz Boas, trabalhou com o modo "particularista histórico" da antropologia. Dentre suas contribuições para a área de antropologia, está a de levar em conta a geografia, o meio ambiente, o material linguístico, as histórias locais e específicas, e, especialmente, os modos de produção. Wagley pertenceu a uma geração de acadêmicos que uniu a antropologia social britânica à antropologia cultural norte-americana. 
movimentações provocam a concorrência no âmbito da atividade educacional. Dessa forma, é em meio a tais enfrentamentos que vão surgindo os sentidos das lutas em que se envolvem os diversos grupos aptos a pleitear o domínio simbólico do campo educacional.

\section{Considerações finais}

Mesmo que o fenômeno da Globalização nos force a pensar que as fronteiras nacionais estão sendo rompidas e ultrapassadas, o "nacional" (e, a reboque, o local/ particular) tem lugar nas novas circunstâncias geradas pela Globalização. Coexistindo com as forças que operam na dimensão supra e transnacional, nota-se que o Estado-Nação continua a induzir a formação de narrativas com o fim de ser ele o gerador da identidade oficial. Trata-se de um controle exercido, especialmente, por intermédio do sistema de ensino.

Por sua vez, no caso brasileiro, se o saber produzido pelo "campo da História" nas décadas de 1970 e 1980 buscou realizar uma crítica ao chamado "ensino tradicional", ao estabelecer uma homologia entre ensinar e pesquisar, com o fim de formar o "pensamento crítico" dos alunos e estes tornarem-se "sujeitos da História" (CORDEIRO, 2000, 1998), a crítica realizada pela perspectiva "diferencialista" à concepção teórica emancipatória marxista, o approache didático de formar o "pensamento crítico" dos alunos continua vigente no currículo "diferencialista" das "relações raciais". Afinal, a ênfase vigente no currículo "diferencialista" das "relações raciais" está em considerar que, por meio da noção de "identidade", é possível "mover consciências" através de um ensino de História, com um conteúdo que seja vinculado às vivências, às experiências cotidianas dos alunos, especialmente, a história social da escravidão, que procura comprovar a resistência cotidiana do escravo negro e sua luta incessante pela liberdade durante o cativeiro.

\section{REFERÊNCIAS}

ABREU, M.; MATTOS, H. Em torno das "Diretrizes curriculares nacionais para a educação das relações étnico-raciais e para o ensino de história e cultura afro-brasileira e africana": uma conversa com historiadores. Estudos Históricos, Rio de Janeiro, v. 21, n. 41 , p. $5-20$, jan./jun. 2008. 
AZEVEDO, C. M. M. de. Anti-Racismo e seus Paradoxos. Reflexões sobre cota racial, raça e racismo. 2. ed. São Paulo: Annablume, 2004.

BRASIL. Lei n. ${ }^{\circ} 10.558$, de 13 de novembro de 2002. Cria o Programa Diversidade na Universidade e dá outras providências. Diário Oficial da União [da] República Federativa do Brasil, Brasília, 14 nov. 2002.

. Lei n. ${ }^{\circ} 10.639$, de 9 de janeiro de 2003. Altera a Lei n. ${ }^{\circ} 9.394$, de 20 de dezembro de 1996, que estabelece as diretrizes e bases da educação nacional, para incluir no currículo oficial da Rede de Ensino a obrigatoriedade da temática "História e Cultura Afro-Brasileira", e dá outras providências. Diário Oficial da União [da] República Federativa do Brasil, Brasília, 2003.

. Lei n. ${ }^{\circ} 12.288$, de 20 de julho de 2010. Institui o Estatuto da Igualdade Racial; altera as Leis n. ${ }^{\circ} 7.716$, de 5 de janeiro de 1989, n. $^{\circ} 9.029$, de 13 de abril de 1995, n. $^{\circ}$ 7.347 , de 24 de julho de 1985 , e n. ${ }^{\circ} 10.778$, de 24 de novembro de 2003. Diário Oficial da União [da] República Federativa do Brasil, Brasília, 2010.

CORDEIRO, J. F. P. O ensino de História e a universidade. Cadernos de Educação (Araraquara), Araraquara, SP, v. 1, n. 1, p. 20-44, 1998.

. A História no centro do debate: as propostas de renovação do ensino de História nas décadas de setenta e oitenta. Araraquara, SP: Laboratório Editorial/ Cultura Acadêmica, 2000. v. 1.

FRASER, N. Reenquadrando a justiça em um mundo globalizado. Lua Nova, São Paulo, n. 77, p. 11-39, 2009.

FREYRE, G. Casa-Grande \& Senzala. Formação da Família Brasileira sob o Regime de Economia Patriarcal. 8. ed. Rio de Janeiro: Livraria José Olympo Editora, [1933] 1954. v. 1.

FRY, P. A persistência da raça: ensaios antropológicos sobre o Brasil e a África austral. Rio de Janeiro: Civilização Brasileira, 2005.

GIANNOTTI, J. A. O Novo Império. Folha de São Paulo, São Paulo, 16/03/2003. Folha Mais!

LÉVI-STRAUSS, C. Mito e Significado. Lisboa: Edições 70, 2007.

2010.

. O Pensamento Selvagem. 11. ed. Trad. Tânia Pellegrine. Campinas, SP: Papirus,

MARTIUS, K. F. von. Como se deve escrever a História do Brasil. O estado de direito entre os autóctones do Brasil. São Paulo: Editora da USP; Belo Horizonte: Livraria Editora Itatiaia, [1845] 1982.

MATTOS, I. R. de. O Tempo Saquarema. São Paulo: Ed. Hucitec/ MinC, 1987.

MELLO, M. V. de. Vers une éducation de la culture; esthétisme et création d'un esprit éthique au Brésil. Paris. Éditions UNESCO/ Harmathan, 2000. 
MEYER, J. W. et al. World society and the nation-State. American Journal of Sociology, v. 103, n. 1, p. 144-181, 1997.

PENA, S. D. J. et al. Color and genomic ancestry in Brazilians. PNAS. Proceedings of the National Academy of Sciences of the United States of America, EUA, v. 100, p. 177-182, 2003.

PEREIRA, J. S. Diálogos sobre o Exercício da Docência - recepção das leis 10.639/03 e 11.645/08. Educ. Real., Porto Alegre, v. 36, n. 1, p. 147-172, jan./abr. 20011. Disponível em: <http://www.ufrgs.br/edu_realidade>. Acesso em: 09/2011.

RAWLS, J. Justiça como Equidade. Uma Reformulação. São Paulo: Martins Fontes, 2003. . O Liberalismo Político. São Paulo: Editora Ática, 2000a. . Uma Teoria da Justiça. São Paulo: Martins Fontes, 2000 b.

SANTOS, R. V.; MAIO, M. C. Antropologia, raça e os dilemas das identidades na era da genômica. Hist. cienc. saude-Manguinhos [on-line], v. 12, n. 2, p. 447-468, 2005. Disponível em: <http://dx.doi.org/10.1590/S0104-59702005000200011>. Acesso em: 16/09/2011.

VOEGELIN, E. From Enlightenment to Revolution. Durham, N.C.: Duke University Press, 1975.

. The History of the Race Idea. Columbia, Mo.: University of Missouri Press, 1997. . The Political Religions. Columbia, Mo.: University of Missouri Press, 2000.

WAGLEY, C. (Org.). Race and class in rural Brazil. Paris: Unesco, 1952.

Texto recebido em 14 de julho de 2012. Texto aprovado em 02 de maio de 2014. 
